\title{
educação

\section{A Intervenção da Inspeção na Avaliação Externa das Escolas: um estudo com base nas perceções de diretores de escolas}

\author{
Arlete Nogueira ${ }^{I}$, Manuela Gonçalves ${ }^{I I}$ \& Jorge \\ Adelino Costa ${ }^{\text {III }}$ \\ Universidade de Aveiro, Portugal
}

\begin{abstract}
Em Portugal, o sistema de avaliação da educação e do ensino não superior surge em 2002, com a publicação da Lei n.o 31/2002, determinando pela mesma via jurídico-normativa que as escolas sejam submetidas a processos de avaliação externa. Este processo avaliativo foi confiado à Inspeção da Educação, a partir de 2007, passando este a ser um dos principais domínios da intervenção inspetiva. O presente estudo tem por objetivo analisar como é percecionado, por diretores de escolas públicas portuguesas, o papel da Inspeção no processo de Avaliação Externa das Escolas. Com uma natureza descritiva, o estudo apoiou-se na aplicação de um inquérito por questionário, respondido por 111 diretores do território de Portugal Continental. Os resultados evidenciam que a Avaliação Externa das Escolas é uma atividade inspetiva valorizada pelos diretores de escolas e desenvolvida em alinhamento, por um lado, com a missão e funções da Inspeção da Educação no sistema educativo, e, por outro, com os objetivos consignados na lei para aquela atividade. Evidencia-se ainda que os diretores de escolas percecionam esta atividade como oportunidade de afirmação da figura do diretor, de acreditação da sua liderança no exercício da sua autonomia.
\end{abstract}

Palavras-chave: Inspeção da educação; Avaliação externa das escolas; Diretores de escolas

\section{N T RO D U Ç Ã O}

A avaliação de escolas em contexto europeu foi mencionada pela Comissão das Comunidades Europeias como fundamental para o desenvolvimento e melhoria das escolas e dos sistemas educativos, na sequência da Cimeira de Lisboa. O interesse pela avaliação advém, essencialmente, das alterações das políticas educacionais, nos últimos 20 anos, por questões de descentralização de poderes e atribuição de maior autonomia às escolas
(Faubert, 2009). Assim, desde os anos 80 e, especialmente, desde a última década do século XX, assiste-se à valorização da avaliação enquanto mecanismo de regulação dos sistemas educativos. Estas transformações começam a sentir-se no âmbito da reforma da Administração, em que o Estado deixa cada vez menos de ser visto como Estado prestador de serviços para ser concebido como Estado Avaliador e regulador (Clímaco, 2011).

Nesta conjuntura, surge em Portugal o sistema de avaliação da educação e do ensino 
não superior, através da publicação da Lei n. ${ }^{\circ} 31 / 2002$, assumido politicamente como aposta na avaliação qualitativa e quantitativa do sistema educativo não superior, de forma a promover a excelência e distinguir as boas práticas, bem como a aprofundar o sentido de responsabilidade e compromisso dos agentes educativos perante a escola, a sociedade e o país, conforme o referido na Proposta de Lei n. ${ }^{\circ}$ 13/IX da Assembleia da República (2002) que antecedeu a formalização e publicação daquele diploma.

De igual modo, aquela Lei objetiva o sistema de avaliação do ensino não superior como instrumento central para a definição das políticas educativas, enquanto suporte sistemático e permanente de informações pertinentes da administração educativa local, regional e nacional e sociedade em geral, bem como o garante da qualidade da educação e credibilidade do desempenho dos estabelecimentos de ensino (Lei n. ${ }^{\circ} 31 / 2002$, $\operatorname{art.}^{\circ} 3 .^{\circ}$ e $\operatorname{art}^{\circ}{ }^{\circ} .^{\circ}$ ). Neste enquadramento, o sistema de avaliação do ensino não superior abrange a educação pré-escolar, os ensinos básicos e secundário da educação escolar, incluindo as modalidades especiais de educação, da rede pública, privada e solidária.

Pela via normativa, as escolas passam a ser submetidas a processos de avaliação e, através dos mesmos, a responsabilizar os seus atores pela qualidade dos serviços prestados, para além de destacar a avaliação externa e a autoavaliação como mecanismos de regulação das políticas educativas. A partir de 2007, a Avaliação Externa das Escolas (AEE) foi atribuída à Inspeção da Educação ${ }^{1}$, competindo ao Conselho Nacional de Educação (CNE) aferir dos seus resultados e, através dos mesmos, propor medidas que se revelem necessárias ao sistema educativo (Lei n. ${ }^{\circ} 31 / 2002$, art. ${ }^{\circ} 12 .^{\circ}$ ). Não obstante se constatar, através da revisão de literatura, a existência de inúmeros estudos com enfoques relevantes e interesses diversificados, relacionados com a AEE (entre os quais, Afonso, 2009; Azevedo, 2007; Barroso, 2004, 2005; Barroso \& Afonso, 2011; Clímaco, 2005, 2011; Costa, 2007; Costa \& Ventura, 2002; Ferreira, 2016; Fialho, 2011; Figueiredo, Leite, \& Fernandes, 2014; Pacheco, 2014, 2015; Silvestre, 2013; Tristão, 2016; Ventura, 2006), o presente estudo visa contribuir para o aprofundamento desta problemática. O estudo objetiva identificar e analisar como diretores de escolas públicas portuguesas do ensino não superior percecionam o papel da Inspeção na AEE, no terreno, de acordo com a missão e funções que lhe são cometidas.

Nesta perspetiva, compreender-se-á que esta temática se reveste de alguma particularidade, por não se conhecerem estudos sobre $o$ tema proposto, bem como pelo facto de este se realizar no final dos dois ciclos de avaliação externa (2006-2011; 2011-2017). Entende-se que o mesmo poderá constituir, numa perspetiva de complementaridade, um elemento contributivo para o aprofundamento

\footnotetext{
${ }^{1}$ Neste estudo é designada por Inspeção da Educação, com abreviatura de Inspeção, sendo atualmente denominada por InspeçãoGeral da Educação e Ciência (IGEC), nos termos do Decreto-Lei n. ${ }^{\circ}$ 125/2011, de 29 de dezembro. A Inspeção é um Departamento dos serviços centrais do Ministério da Educação que deve ser lido à luz da organização das áreas governamentais do XXI Governo Constitucional (Decreto-Lei n. ${ }^{\circ}$ 251-A/2015, de 17 de dezembro.).Tem como missão e funções “assegurar a legalidade e regularidade dos atos praticados pelos órgãos, serviços e organismos do Ministério da Educação e Ciência (MEC) . . . ou sujeitos à tutela do respetivo membro do Governo, bem como o controlo, a auditoria e a fiscalização do funcionamento do sistema educativo, no âmbito da educação pré-escolar, da educação escolar, compreendendo os ensinos básico, secundário e superior” (Decreto-Lei n. ${ }^{\circ} 125 / 2011$, de 29 de dezembro, art. ${ }^{\circ} 11 .^{\circ}$, ponto 1$)$.
} 
do conhecimento da Inspeção da Educação em Portugal e uma reflexão sobre o papel da Inspeção na avaliação das escolas.

\section{Avaliação Externa das ESCOLAS EM PORTUGAL}

Nas últimas décadas houve necessidade por parte dos diferentes Estados nacionais de encontrar múltiplas formas para responder à emergência de novos quadros sociais resultantes do processo de globalização (Santos, 2001). É neste cenário que as recomendações de organismos europeus, através dos seus programas de assistência e aconselhamento internacionais, defendem a avaliação de escolas como percursora da sustentabilidade, no que respeita à equidade de recursos, garantia de qualidade da educação e melhoria dos sistemas educativos. Em consonância, emergem e difundem-se discursos que apontam para a necessidade de assegurar a qualidade, a eficiência e a eficácia dos serviços prestados e dos resultados alcançados, no que respeita à educação escolar, considerando que é esta o elemento central na promoção do desenvolvimento pessoal, educativo, cívico e profissional de todos os cidadãos (OCDE, 2013; Santiago, Donaldson, Looney, \& Nusche, 2012).

Não obstante assistir-se, desde inícios da década de 80, à emergência de um novo sentido para a avaliação em educação (perspetivada enquanto mecanismo de regulação dos sistemas educativos e, consequentemente, das escolas), foi a partir da última década do século XX, em Portugal, que o interesse e mobilização do conhecimento pela avaliação institucional (das escolas) mais se destacou. Esta importância começa a relevar-se em todos os países europeus, independentemente das ideologias políticas, devido aos processos de descentralização de poderes e responsabilidades do Estado para o local, isto é, pela atribuição de maior autonomia às escolas, bem como pela expansão da lógica de mercado para o campo social, salientando-se a necessidade de promover valores de competitividade, eficiência, eficácia e a qualidade do serviço prestado (Barroso \& Afonso, 2011; Clímaco, 2011; Pacheco, 2014, 2015).

Assim, a prestação de contas, a responsabilização e o compromisso em melhorar os mecanismos dos sistemas de educação nacionais e internacionais, a sua organização e funcionamento e a eficácia na obtenção de melhores resultados são referências substantivas em relatórios produzidos por organismos nacionais e internacionais (Conselho Nacional de Educação, 2011, 2015; OCDE, 2013; Santiago et al., 2012). Esta "cultura de performatividade" (Ball, 2001) tem vindo a consolidar-se como paradigma das políticas públicas dos mais diversos países, através de processos de regulação nacionais e transnacionais, enquanto ideário estandardizado de normas, discursos e instrumentos, na conceção e legitimação de políticas de reforma (Barroso, 2004).

Deste modo, abre-se caminho para a avaliação educacional como mecanismo de tecnologia política (Brandão \& Magalhães, 2011), quer pela emergência de políticas internacionais de cariz neoliberal (produtividade e prestação de contas), quer por uma nova visão de gestão pública. Na base desta discussão, mobilizase a ideia de que, no contexto educacional, a tradicional avaliação feita através do controlo tenda a passar para uma avaliação desenhada pela definição de objetivos e sua efetiva quantificação.

Esta perspetiva para que tem propendido a avaliação das escolas (medidas pelos resultados) segue, segundo Afonso (2009), um 
modelo específico, importado de contextos económicos - accountability -, patente nos modelos de avaliação de desempenho docente, na autoavaliação das escolas, nos rankings das escolas, na aplicação de testes estandardizados para a avaliação do processo de ensino-aprendizagem dos alunos (provas de aferição e exames nacionais). Porém, é no domínio da administração educacional que a avaliação das escolas tem sido mais discutida, nomeadamente quanto aos aspetos relativos ao garante de princípios de transparência, de direito à informação e de responsabilização dos serviços prestados, e equacionada numa perspetiva tridimensional: avaliação, prestação de contas e responsabilidade (Afonso, 2009).

Afonso (2014), quando se refere à primeira fase de Estado avaliador, convoca a ideia de que a avaliação só fará sentido se forem analisadas as interdependências/interseções entre as avaliações realizadas ao nível nacional e as avaliações e orientações a que muitos Estados aderem, ou se vinculam, em decorrência de serem membros de agências internacionais como a OCDE, organismo considerado como sendo o think tank das políticas globais (Mendes, 2009). No entanto, este acautelamento não interfere na pertinência da avaliação de escolas, na perspetiva de potenciar a produção de conhecimento e de informação sobre o funcionamento das escolas, o diagnóstico das necessidades e a promoção da garantia da qualidade das práticas pedagógicas e da melhoria dos resultados da educação (Fialho, 2011). Esta tendência converge, entre outros fatores, do reconhecimento da necessidade de uma maior autonomia às escolas, através de uma diminuição “da participação e envolvimento direto dos poderes centrais (Estado) na prestação do serviço educativo, na atribuição de mais competências às escolas e na maior 'liberdade' das escolas para a organização do trabalho desenvolvido" (Figueiredo et al.,
2014, p. 123).

Por iniciativa do XV Governo Constitucional, o sistema de avaliação da educação do ensino não superior surge em Portugal enquanto linha estratégica nacional, através da publicação da Lei n. ${ }^{\circ} 31 / 2002$, como medida obrigatória e sistemática, em termos de avaliação das escolas. Desde logo, a AEE é apresentada na perspetiva da (re)configuração triárquica do termo, isto é, como medida política, reconhecida como instrumento fundamental na reforma das instituições escolares (das escolas); medida social, em função da pressão sobre os resultados e consequente exigência de responsabilidade social (Costa \& Ventura, 2002), mas também como resposta a lógicas de mercado (qualidade de sentido público tendo por retaguarda o Estado); e medida (in) formativa, focada no fornecimento atempado de informações pertinentes sobre o sistema educativo, quer às comunidades locais, quer às organizações nacionais e internacionais.

Se, por um lado, há estudos (por ex., Pacheco, 2014) que referem a AEE como um modelo de avaliação que gera potenciais dinâmicas, aos vários níveis (diretores de escolas, coordenadores de departamento, professores, alunos, comunidade), outros consideram a AEE uma ação "hiperburocrática" sobre as escolas, ou mesmo um meio de comparação de resultados escolares mensuráveis, regidos por lógicas de accountability, consentâneos com as exigências do mercado (Afonso, 2009; Lima, 2011). Segundo Afonso (2009), a AEE é uma forma de deslocalização e de desresponsabilização, em relação a problemas imputáveis aos governos (gestão de recursos), mas que são transferidos para a responsabilidade dos diretores de escolas, enquanto gestores das organizações educativas.

Decorrente do articulado do diploma (Lei n. $\left.{ }^{\circ} 31 / 2002\right)$ que institui a avaliação do ensino não superior, 
a avaliação externa, a realizar no plano nacional ou por área educativa, em termos gerais ou em termos especializados, assenta em aferições de conformidade normativa das atuações pedagógicas e didáticas e de administração e gestão, bem como de eficiência e eficácia das mesmas ... podendo, igualmente, assentar em termos de análise da qualificação educativa da população, desenvolvendo-se neste caso, se necessário, fora do âmbito do sistema educativo. (art. ${ }^{\circ} 8 .^{\circ}$, pontos 1 e 2$)$

Ainda segundo o mesmo diploma, a AEE estrutura-se com base nos seguintes elementos: a) sistema de avaliação das aprendizagens em vigor, tendente a aferir o sucesso escolar e o grau de cumprimento dos objetivos educativos definidos como essenciais pela administração educativa; b) sistema de certificação do processo de autoavaliação; c) ações desenvolvidas, no âmbito das suas competências, pela Inspeção-Geral de Educação; d) processos de avaliação, geral ou especializada, a cargo dos demais serviços do Ministério da Educação; e) estudos especializados, a cargo de pessoas ou instituições, públicas ou privadas, de reconhecido mérito (Lei n. ${ }^{\circ} 31 / 2002$, art. ${ }^{\circ} 8 .^{\circ}$, ponto 3).

Assim, é nesta configuração legislativa que à Inspeção foi cometida a responsabilidade de proceder à AEE nas escolas ${ }^{2}$, conforme o determinado no Decreto Regulamentar n. $^{\circ}$ $15 / 2012$, e demais legislação ${ }^{3}$, em conjugação com o determinado na alínea c), ponto 3 , da Lei n. ${ }^{\circ}$ 31/2002.

Em 2006, o XVII Governo Constitucional procede à constituição de um Grupo de
Trabalho para a Avaliação das Escolas (GTAE), através da publicação do Despacho Conjunto n. ${ }^{\circ} 370 / 2006$, de 3 de maio, com o objetivo de estudar e propor os modelos de autoavaliação e de avaliação externa dos estabelecimentos de educação pré-escolar e dos ensinos básico e secundário. Congruente com aquele discurso político-normativo, o GTAE, depois de definir os procedimentos e as condições necessárias à conceção e operacionalização de um modelo de AEE, aplica-o (fase-piloto), ainda no ano letivo de 2006-2007, a 24 escolas e agrupamentos de escolas. Decorrente da avaliação dessa fase-piloto e após alguns ajustamentos, o desenvolvimento do programa de AEE passa, em 2007, para a responsabilidade da Inspeção da Educação.

A propósito da génese daquele programa, considerando o intervalo temporal que baliza todo o processo em Portugal, isto é, desde a sua emergência em contexto legislativo (2002) até à sua efetiva implementação no terreno (2006), poder-se-á afirmar que foi um processo moroso, considerando as diferentes iniciativas tomadas nesta matéria: i) a publicação da Lei n. ${ }^{\circ} 31 / 2002$; ii) a criação do GTAE, em 2006, ano em que se concebe e experimenta o modelo de AEE; e iii) a consequente aplicação e generalização do modelo em 2007 2008, já sob a responsabilidade da Inspeção. Esta morosidade justifica-se, em parte, por razões inerentes à instabilidade política $\mathrm{e}$ governativa ${ }^{4}$. Na verdade, ao longo da história da educação em Portugal tem sido factual que, em relação a reformas educativas, os processos arrastam-se no espaço-tempo, ora por efeitos de negociação/contratualização de diferentes

\footnotetext{
${ }^{2}$ Utiliza`se o termo 'escola' para designar um agrupamento de escolas ou uma escola não agrupada·

${ }^{3}$ Decreto Regulamentar n. ${ }^{8} 81-B / 2007$, de 31 de julho.

${ }^{4}$ Esta instabilidade política caracterizou-se fundamentalmente, por mudanças frequentes de governos que estiveram no poder e nos seus programas e filosofias (XV Governo Constitucional, Portugal (2002-2004); XVI Governo Constitucional, Portugal (20042005); XVII Governo Constitucional, Portugal (2005-2009).
} 
entidades nacionais, regionais e locais, ora por pressão dos vários grupos intervenientes no respetivo setor e/ou mesmo por falta de recursos humanos, financeiros e patrimoniais.

Importa referir que a responsabilidade conferida, nesta matéria, à Inspeção decorre, não só das atribuições que lhe são cometidas por lei, enquanto serviço central do Ministério da Educação, como também da experiência anteriormente adquirida no desenvolvimento de programas no domínio da avaliação externa, destacando-se, entre os demais ${ }^{5}$, o Programa de Avaliação Integrada das Escolas (PAIE), entre 1999 e 2002. Refere-se o PAIE por se considerar que foi um dos mais emblemáticos programas, no contexto da atividade inspetiva, representando um "marco" num tempo novo (viragem do milénio) da Inspeção, à qual se procurou associar a passagem de "um papel predominantemente 'fiscalizador', de verificação da conformidade normativa, para um papel de acompanhamento e avaliação" (Costa \& Ventura, 2002, p. 108). A menção ao PAIE é justificada pelo facto de o modelo proposto para a AEE, em 2006, enfatizar alguns dos aspetos do então modelo do PAIE (1999-2002). Esta prerrogativa assenta nas expressões "garantir a qualidade", "identificar pontos fortes e pontos fracos tendo em conta a melhoria" "induzir práticas de autoavaliação das escolas" (Inspeção-Geral da Educação, 2001; Inspeção-Geral da Educação e Ciência, 2017), léxico desde logo assumido na forma e conteúdo do relatório produzido pelo Grupo de Trabalho para a Avaliação Externa (Despacho Conjunto n. ${ }^{\circ} 370 / 2006$ ).

Em termos de responsabilidade da Inspeção, e no que concerne à operacionalização da AEE, constata-se que desde os anos de 2007/2008 a AEE faz parte do Plano Anual de Atividades da Inspeção, enquanto domínio estratégico da ação inspetiva. Deste modo, a Inspeção, de acordo com a missão e funções que lhe são cometidas, enquadra esta atividade no seu IV programa operacional, definindo como objetivos estratégicos para a atividade da AEE:

i) promover o progresso das aprendizagens e dos resultados dos alunos, identificando pontos fortes e áreas prioritárias para a melhoria do trabalho das escolas; ii) incrementar, a todos os níveis, a responsabilização, validando as práticas de autoavaliação das escolas; iii) fomentar a participação na escola da comunidade educativa e da sociedade local, oferecendo um melhor conhecimento público do trabalho das escolas; e iv) contribuir para a regulação da educação, dotando os responsáveis pelas políticas educativas e pela administração das escolas de informação pertinente. (Inspeção-Geral da Educação e Ciência, 2017, p. 58)

No presente quadro institucional e com a efetiva concretização da AEE, no terreno, os sentidos de eficácia, qualidade e melhoria dos serviços prestados nas escolas passam a fazer parte das preocupações do quotidiano da administração e gestão das escolas, e, por conseguinte, das suas lideranças, os diretores ${ }^{6}$.

Até à data da realização deste trabalho, a Inspeção concluiu dois ciclos de AEE nas escolas do sistema de ensino não superior (jardins de infância, escolas básicas e secundárias públicas), sendo que o primeiro

${ }^{5}$ Sobre os programas realizados pela Inspeção' no domínio da avaliação externa' ver informação disponível em: https:/www'igec· mec.pt/content ${ }^{01} \cdot a s p ?$ BtreeID $={ }^{03 / 02} \&$ treeID $=03 / 02 / 00 / 05 \&$ auxID $=$

${ }^{6}$ Os diretores de escola em Portugal são o órgão de administração e gestão das escolas "com competências para executar a nível local as medidas de política educativa ... a quem poderão ser assacadas as responsabilidades pela prestação de serviço público de educação e pela gestão de recursos públicos postos à sua disposição" (Decreto-Lei n. ${ }^{\circ}$ 75/2008, de 22 de abril, preâmbulo e art. ${ }^{\circ} 18 .^{\circ}$ ). 
ciclo de avaliação terminou em junho de 2011 e o segundo ciclo em 2017. Para a concretização desta atividade foram constituídas equipas de avaliação externa, dois inspetores e um perito externo à Inspeção.

No sentido de prosseguir o $3 .^{\circ}$ ciclo da AEE (2017-2018), foi formado um Grupo de Trabalho com a missão de analisar os referenciais e metodologias do Programa de Avaliação Externa das Escolas (Despacho n. ${ }^{\circ}$ 13342/2016).

Por conseguinte, é neste contexto que o presente estudo se fundamenta e interroga as perceções de diretores de escolas públicas portuguesas sobre o papel da Inspeção na AEE, procurando identificar e analisar, de forma específica, como estes atores o percecionam, no terreno.

\section{METODOLOGIA}

\subsection{OPÇÕES E PROCEDIMENTOS METODOLÓ G ICOS}

Este estudo, com uma natureza descritiva (Coutinho, 2015), foi operacionalizado através da recolha de dados pela aplicação de um inquérito por questionário, justificandose a opção por esta técnica de investigação pela faculdade de ser aplicada a um conjunto alargado de indivíduos, permitindo efetuar o levantamento de um grande número de informações (Coutinho, 2015; Tuckman, 2012), ao mesmo tempo que faculta tornar inteligível a complexidade (Gonçalves, 2012) da realidade em estudo.

Este trabalho é o recorte de um projeto de doutoramento, em curso, sobre a Inspeção da Educação em Portugal. O estudo, com uma natureza que cruza as vertentes qualitativa e quantitativa, foi operacionalizado através da aplicação de um inquérito por questionário (IQ) dirigido aos diretores de escola do território continental português. O questionário, construído com base de numa grelha de indicadores, está organizado por dimensões, quatro das quais atinentes à Inspeção da Educação, a saber: i) Dimensão A. Missão/Funções; ii) Dimensão B. Atividades Inspetivas; iii) Dimensão C. Práticas de Ação e Intervenção Inspetiva; iv) Dimensão $D$. Mudanças e Expectativas. Acresce que estas foram operacionalizadas, em termos de resposta, a partir de uma escala tipo Likert, em que 1 é "nada importante" e 5 "muito importante”.

Os dados apresentados neste estudo correspondem a um dos cinco eixos da práxis inspetiva: (o Programa IV - Avaliação) concernente à atividade Avaliação Externa das Escolas, integrada na Dimensão B. Atividades Inspetivas. Aquele eixo (AEE) contém 11 itens (Tabela 1), definidos com base no que fundamenta e estabelece o discurso normativo, especificamente no que concerne à missão e funções da Inspeção, e, ainda, à responsabilidade, coordenação e intervenção deste organismo no processo de AEE (Decreto Regulamentar n. ${ }^{\circ}$ 15/2012; Inspeção-Geral da Educação e Ciência, 2017; Lei n.o 31/2002, art. $^{\circ} 8 .^{\circ}$ ).

Após a elaboração do instrumento, este foi sujeito a um painel de peritos (três diretores de escola aposentados) e foi utilizada a técnica think aloud, por forma a avaliar a adequação dos indicadores aos conteúdos pretendidos (Charters, 2003; Terwee et al., 2007). Este grupo, depois de proceder à leitura e análise do questionário, apresentou algumas propostas de alteração a alguns itens, que foram consideradas. Em fase posterior, o IQ passou por um pré-teste, aplicado aos mesmos elementos do painel de peritos, objetivando avaliar a inteligibilidade e compreensão do instrumento (Coutinho, 2015), bem como determinar o tempo necessário ao seu 
preenchimento, e foi discutida a observância dos princípios éticos, nomeadamente o direito à informação sobre o objeto de estudo, a liberdade em colaborar no estudo e o anonimato (Tuckman, 2012). Após o pré-teste procedeu-se à formalização final do inquérito por questionário através do preenchimento digital, com recurso à ferramenta docs.google. com. Por último, identificou-se um link que foi enviado por carta/convite, via correio eletrónico, a todos os diretores de escolas do território continental português, a 19 de dezembro de 2017, ficando disponível online até 30 de janeiro de 2018.

Após aquela data, os dados foram recolhidos (online) e tratados, com recurso ao software Microsoft Office Excel, versão 2016, através de estatísticas descritivas (frequências absolutas e relativas, médias aritméticas e desvio-padrão [DP]).

\subsection{A}

Para o envio da carta/convite aos diretores de escolas (811) foi solicitada a colaboração do Presidente da Associação Nacional de Diretores de Agrupamentos e Escolas Públicas (ANDAEP) e, daquele total, entre 19 dezembro de 2017 e 30 de janeiro de 2018, preencheram e submeteram o questionário, online, 111 indivíduos, sendo que a amostra deste estudo corresponde a $13,7 \%$ do total de diretores convidados a responder.

Os respondentes apresentam umaidade média de 55 anos, sendo $59 \%$ do género masculino, 90,1\% diretores de agrupamento de escolas e $9,9 \%$ diretores de escolas não agrupadas. Se se considerar que $99,1 \%$ dos diretores respondentes são professores do quadro de nomeação definitiva e $84 \%$ completam, à data da administração do IQ, mais de 4 anos no cargo de diretor, e, ademais, que $14 \%$ dos participantes perfaziam 10 anos no cargo, poder-se-á dizer que a amostra é constituída por um grupo de diretores de escola estável e, concomitantemente, experiente, no que concerne a questões diretamente relacionadas com a vertente temática.

\section{APRESENTAÇÃO E DISCUSSÃo DE RESULTADOS}

Tomando por base os resultados constantes na Tabela 1, referentes às perceções de diretores de escolas sobre o papel da Inspeção, no âmbito da atividade de Avaliação Externa das Escolas, é possível destacar alguns aspetos considerados relevantes sobre como aqueles atores o percecionam no terreno.

Desde logo, constata-se que os diretores de escolas que participaram neste estudo consideram o papel da Inspeção na AEE, globalmente, como importante (pela observação dos resultados obtidos em todos os indicadores, situados entre média $=3,29$; $\mathrm{DP}=1,12$, item 7 , e média $=3,98 ; \mathrm{DP}=0,86$, item 11 - Tabela 1). Contudo, como se verá, a importância atribuída ao papel da Inspeção na AEE parece encontrar-se associada, sobretudo, ao determinado na lei, isto é, numa visão consonante com os diplomas em matéria legislada (Decreto-Lei n. ${ }^{\circ}$ 15/2012; Lei n.o 31/2002).

Assim, e da leitura global da Tabela 1, ressalta, em primeiro plano, que os diretores atribuem uma elevada importância à função desempenhada pela Inspeção na AEE em questões relacionadas com: "regulação da educação, à luz dos normativos legais em vigor", item 11 (média $=3,98 ; \quad \mathrm{DP}=0,86$ ); “identificar pontos fortes e áreas prioritárias para a melhoria do trabalho das escolas", item 10 (média=3,98; DP=0,88); "refletir com o diretor", item 1 (média=3,95; DP=1,05). No que concerne a aspetos inerentes à informação fornecida aos órgãos responsáveis pela gestão 
TA B EL A 1

Perceções de Diretores Sobre o Papel da Inspeção na Avaliação Externa de Escolas ( $n=111$ )

\begin{tabular}{|c|c|c|}
\hline Indicadores & Média & $\begin{array}{l}\text { Desvio- } \\
\text { padrão }\end{array}$ \\
\hline 1- Refletir com o diretor & 3,95 & 1,05 \\
\hline $\begin{array}{l}\text { 2- Fomentar a participação da escola na comunidade educativa e } \\
\text { na sociedade local }\end{array}$ & 3,68 & 0,97 \\
\hline $\begin{array}{l}\text { 3- Oferecer um melhor conhecimento público do trabalho } \\
\text { desenvolvido pelos agrupamentos de escolas e escolas não } \\
\text { agrupadas }\end{array}$ & 3,70 & 0,95 \\
\hline $\begin{array}{l}\text { 4- Fornecer informação pertinente aos responsáveis pelas políticas } \\
\text { educativas e pela administração das escolas }\end{array}$ & 3,94 & 0,98 \\
\hline $\begin{array}{l}\text { 5- Garantir a credibilidade do desempenho dos agrupamentos de } \\
\text { escolas e escolas não agrupadas }\end{array}$ & 3,71 & 1,00 \\
\hline $\begin{array}{l}\text { 6- Validar as práticas de autoavaliação dos agrupamentos de } \\
\text { escolas e escolas não agrupadas }\end{array}$ & 3,87 & 0,93 \\
\hline 7- Observar a prática pedagógica dos docentes & 3,29 & 1,12 \\
\hline $\begin{array}{l}\text { 8- Analisar os aspetos positivos e negativos da prática pedagógica } \\
\text { dos docentes }\end{array}$ & 3,41 & 1,04 \\
\hline $\begin{array}{l}\text { 9- Auscultar os alunos relativamente às práticas pedagógicas dos } \\
\text { docentes }\end{array}$ & 3,44 & 1,08 \\
\hline $\begin{array}{l}\text { 10- Identificar pontos fortes e áreas prioritárias para a melhoria do } \\
\text { trabalho das escolas }\end{array}$ & 3,98 & 0,88 \\
\hline $\begin{array}{l}\text { 11- Contribuir para a regulação da educação, à luz dos normativos } \\
\text { legais em vigor }\end{array}$ & 3,98 & 0,86 \\
\hline
\end{tabular}

e administração das escolas, saliente-se, nesse âmbito, que os diretores também consideram o papel da Inspeção nesta atividade de primordial importância, tendo em conta o item 4 (média $=3,94 ; \mathrm{DP}=0,98$ ).

Continuando a observar a Tabela 1, e no que se refere a aspetos que têm a ver com a validação das práticas intrínsecas à autoavaliação (item 6 , com média=3,87;
$\mathrm{DP}=0,93)$, a "credibilidade do desempenho" das escolas (item 5 , com média $=3,71 ; \mathrm{DP}=1,00$ ) e o "oferecer um melhor conhecimento público do trabalho desenvolvido" pelas mesmas (item 3, com média $=3,70$; $\mathrm{DP}=0,95)$, os diretores percecionam o papel da Inspeção como importante, embora lhe atribuam, como se verifica, um menor grau de relevo, comparativamente com os aspetos 
anteriores. De igual modo, estes resultados, se interpretados à luz do consignado no DecretoLei n. ${ }^{\circ} 75 / 2008$, evidenciam que os diretores parecem assumir o seu estatuto, enquanto órgão responsável pela execução das políticas educativas, tanto mais se se considerar o grau de importância que atribuem a si mesmos (item 1, Tabela 1).

Ademais, se observados os itens associados a questões de regulação da educação, em que os diretores apontam claramente para o contributo da Inspeção nesse âmbito (item 11, Tabela 1), parece ser possível constatar, por um lado, uma certa afirmação por parte destes diretores no que diz respeito às suas atribuições, enquanto órgão de gestão e administração das escolas, e, por outro, em relação ao que compete à Inspeção, enquanto serviço central do Ministério da Educação.

Por sua vez, estes resultados parecem explicitar que a Inspeção, para estes diretores, não se desprende do que lhe determina a lei, em termos do cumprimento da sua missão e funções, como, por exemplo, "assegurar a legalidade" (Decreto Regulamentarn. ${ }^{0} 15 / 2012$ ) e "garantir a credibilidade do desempenho dos estabelecimentos de educação e de ensino" (Lei n. ${ }^{\circ} 31 / 2002$, alínea f)). Este aspeto parece estar em sintonia com a ideia de que "a escola e os seus atores são condenados à reprodução normativa, negando-se-lhes a possibilidade de se auto-organizarem, de produzirem as suas próprias regras e de tomarem decisões" (Fonseca, 2010, p. 152).

Nesta perspetiva, estes resultados parecem evidenciar a importância conferida pelos diretores à Inspeção na atividade da AEE, tanto mais que, por este meio, os diretores vêm, por um lado, certificar e legitimar o seu trabalho junto do poder central (responsável pela determinação das políticas educativas e pela administração das escolas), e, por outro, o facto de a Inspeção identificar pontos fortes e áreas prioritárias possibilita que os diretores nas escolas rentabilizem esse aspeto, como forma de melhorar o trabalho e o desempenho (itens 4 e 10, Tabela 1).

Com efeito, a Inspeção na AEE, através da produção e publicitação de um relatório no final da atividade, valida interna e externamente os resultados, divulga as performances do trabalho das escolas e a imagem pública destas perante o poder central e o interesse das comunidades que serve, e, ao fazê-lo, segundo Fialho (2011), permite aos diretores uma maior acreditação do seu trabalho na perspetiva de potenciar a produção de conhecimento e de informação sobre o funcionamento das escolas, o diagnóstico das necessidades e a promoção da garantia da qualidade das práticas pedagógicas e da melhoria dos resultados da educação.

A ser assim, as perceções dos diretores parecem entrecruzar-se com um outro fundamento, este produzido no âmbito do discurso político-normativo, no que concerne aos objetivos preconizados para a avaliação das escolas do sistema do ensino não superior: "dota a administração educativa local, regional e nacional, e a sociedade em geral, de um quadro de informações sobre o funcionamento do sistema educativo" (Lei n. ${ }^{\circ}$ 31/2002, alínea b), sendo que a Inspeção na AAE vai ao encontro daqueles particulares termos consignados naquela Lei.

$\mathrm{Na}$ mesma linha, segundo Afonso (2009), a AEE é uma forma de deslocalização e de desresponsabilização, em relação a problemas imputáveis aos governos (gestão de recursos), mas que são transferidos para a responsabilidade dos diretores de escola, enquanto gestores das organizações educativas.

Porém, se os resultados apresentados anteriormente parecem indicar que os diretores conferem à Inspeção um relevante papel na atividade da AEE, uma outra leitura, não menos expressiva, é a de que os mesmos 
diretores atribuem uma menor importância ao seu papel nas questões relacionadas com "observar a prática pedagógica" (média=3,29; $\mathrm{DP}=1,12$ ), "analisar os aspetos positivos $\mathrm{e}$ negativos da prática pedagógica dos docentes" (média=3,41; DP=1,04) e "auscultar os alunos relativamente às práticas pedagógicas dos docentes" (média $=3,44 ; \mathrm{DP}=1,08$ ), itens 7,8 e 9, respetivamente. Perante estes resultados, a ação da Inspeção no âmbito pedagógico é, portanto, nitidamente, menos valorizada por estes diretores.

Todavia, atente-se que estes resultados devem ser lidos tendo em conta que os respondentes (diretores de escolas) são atores intervenientes que se encontram em exercício de funções no antes e no durante dos dois ciclos de avaliação AEE (2006-2017) e são, também, intervenientes na construção e evolução do Regime Jurídico de Autonomia, Administração e Gestão Escolar (Decreto-Lei n. $\left.{ }^{\circ} 75 / 2008\right)$. Desde logo, se contextualizados nesse quadro, os resultados permitem aduzir, de acordo com Pacheco (2014), que, se há estudos que referem a AEE como um modelo de avaliação que gera potenciais dinâmicas aos vários níveis (diretores de escolas, coordenadores de departamento, professores, alunos, comunidade), outros consideram a AEE uma ação "hiperburocrática" sobre as escolas, ou mesmo um meio de comparação de resultados escolares mensuráveis, regidos por lógicas de accountability, consentâneos com as exigências do mercado (Afonso, 2009; Lima, 2011).

Com efeito, a intervenção da Inspeção nos aspetos de âmbito pedagógico, relacionados com as práticas dos docentes e a observação de aulas (processos de ensino-aprendizagem, situados no interior das escolas e das salas de aulas), lida à luz destes resultados como menos importante, poderá ser interpretada, na perspetiva de Azevedo (2007), como uma "intromissão" e "fonte de resistência", no domínio do processo de ensino-aprendizagem e prática pedagógica, constituindo uma ingerência na "autonomia" dos professores (sala de aula), enquanto serviço central da administração (controlo e fiscalização). Por conseguinte, estes resultados vão no sentido de que o papel da Inspeção é considerado mais de controlo do que de apoio, ou mesmo de supervisão da educação escolar (Ventura, 2006).

Num outro campo, este relativo a processos internos de gestão e organização pedagógica das escolas (envolvimento dos diferentes atores escolares), as perceções dos diretores parecem direcionar-se no sentido de acautelar as informações que possam ser plasmadas nos relatórios produzidos pela Inspeção, no final de cada intervenção, neste caso no âmbito da atividade da AEE (itens 4, 6 e 10). Isto porque os elementos constantes nesses relatórios (Fonseca \& Costa, 2018) são utilizados muitas vezes pelos diretores enquanto fatores essenciais nas dinâmicas e comprometimento dos diferentes intervenientes no processo de ensino-aprendizagem (órgãos de gestão e administração, professores, alunos, pessoal auxiliar da ação educativa, pais/encarregados de educação). Dir-se-á que este processo tende para uma interação imprescindível à autoavaliação das escolas como contributo para "o desenvolvimento organizacional da escola, ou seja, para o reforço do profissionalismo e das competências docentes, para a melhoria das práticas de ensino-aprendizagem e para o bem-estar dos elementos da comunidade educativa" (Costa, 2007, p. 229).

Assim sendo, o papel da Inspeção na AEE parece contribuir, nas perceções destes diretores, para uma reafirmação da autonomia das escolas (diferenciação), em termos do grau de execução dos diferentes programas e aumento de capacidade de decisão, na 
implementação dos seus projetos educativos (Costa \& Ventura, 2002).

Igualmente, os resultados apresentados (Tabela 1) permitem desenhar uma fronteira: de um lado, a Inspeção, enquanto serviço central do Ministério da Educação, que, no exercício da sua missão e funções (Decreto Regulamentar n. ${ }^{\circ}$ 15/2012; Lei n. $\left.{ }^{\circ} 31 / 2002\right)$, está comprometida com a regulação da educação em domínios de informar os responsáveis políticos sobre $\mathrm{o}$ andamento do processo da AEE nas e em cada escola, contribuir para a credibilização das escolas e creditação do serviço público que prestam (respetivamente, itens 11, 10 e 4); de um outro, os diretores de escolas "com autoridade necessária para desenvolver o projeto educativo da escola e executar localmente as medidas de política educativa", no que concerne a questões organizacionais e técnicopedagógicas, relacionadas com a observação da prática dos docentes (sala de aula), a auscultação dos alunos e a análise de aspetos positivos e negativos da prática pedagógica dos docentes, se considerados estes resultados, designadamente os observados nos itens 1, 7, 8 e 9.

Logo, se atenta a leitura dos precedentes resultados, esta posição por parte dos diretores poderá afluir, entre outros fatores, para o reconhecimento da necessidade de uma maior autonomia das escolas, através de uma diminuição "da participação e envolvimento direto dos poderes centrais (Estado) na prestação do serviço educativo, na atribuição de mais competências às escolas e na maior 'liberdade' das escolas para a organização do trabalho desenvolvido" (Figueiredo et al., 2014, p. 123). Com efeito, os resultados parecem propender para a afirmação da liderança por parte dos diretores de escolas (órgão executor local) e a assunção das suas competências na implementação de políticas educativas. Sendo que, a visão destes diretores, se lida à luz dos presentes resultados, permite ir ao encontro do que refere Silvestre (2013), de que a AEE tende para a credibilização das lideranças (os diretores de escolas).

\section{CONSIDERAÇÕES FINAIS}

O sistema de avaliação da educação do ensino não superior surge em Portugal por iniciativa do XV Governo Constitucional enquanto linha estratégica nacional, através da publicação da Lei n. ${ }^{\circ} 31 / 2002$. Decorrente daquele contexto político-normativo, o programa AEE emerge, em 2006, como resultado de um Grupo de Trabalho criado para o efeito e, a partir de 2007, passa efetivamente para a responsabilidade da Inspeção, tornando-se desde então parte do planeamento anual das atividades inspetivas desenvolvidas nas escolas.

Tal como foi referido anteriormente, a AEE assenta num conjunto de pressupostos e objetivos e, portanto, é nesse quadro que este estudo se situa, procurando identificar e analisar o papel da Inspeção enquanto serviço central do Ministério da Educação.

Globalmente, os resultados permitem sustentar que os diretores de escolas, relativamente ao papel da Inspeção na AEE, dão maior importância às questões inerentes ao controlo e regulação do sistema educativo, em detrimento das questões técnico-pedagógicas, destacando-se, para tal, que:

- Estes diretores conferem uma maior relevância ao papel da Inspeção nos aspetos tendentes à identificação de pontos fortes $\mathrm{e}$ áreas prioritárias para melhoria do trabalho das escolas e regulação da educação, à luz dos normativos legais em vigor; e uma menor importância no que concerne ao seu papel no âmbito de questões pedagógicas, seja observação da prática pedagógica dos docentes, seja auscultar os alunos e/ou analisar aspetos positivos e negativos da prática pedagógica dos docentes;

- Os resultados obtidos tendem para a evidência de que os diretores de escola 
caminham para a afirmação do seu estatuto enquanto órgão responsável pela execução das políticas educativas nos territórios educativos que gerem, remetendo para a Inspeção aspetos relacionados com a missão e funções que lhe foram consignadas normativamente, enquanto serviço central do Ministério da Educação;

- Se aborda um tema não isento de grande sensibilidade, suscetível de produzir vieses, em função do socialmente desejável, mesmo considerados o anonimato e a confidencialidade do instrumento utilizado;

- Tratando-se de um estudo realizado no final de dois ciclos de AEE, sob a responsabilidade e coordenação da Inspeção, considera-se pertinente que estas questões devam ser aprofundadas, nomeadamente através de entrevistas a diretores de escolas.

\section{REFERÊ NCIAS}

Afonso, A. J. (2009). Políticas avaliativas e accountability em educação - Subsídios para um debate ibero-americano. Sísifo. Revista de Ciências da Educação, 9, 57-70.

Afonso, A. J. (2014). Questões, objetos e perspetivas em avaliação. Avaliação, 19(2), 487-507.

Azevedo, J. M. (2007). Estudo: Avaliação das escolas: Fundamentar modelos e operacionalizar processos. In Conselho Nacional da Educação (Org.), Avaliação das escolas - Modelos e processos (Actas do seminário) (pp. 13-99). Lisboa, Portugal: Conselho Nacional da Educação.

Ball, S. (2001). Diretrizes e políticas globais e relações políticas locais de educação. Currículo sem Fronteiras, 1(2), 99-116.

Barroso, J. (2004). A regulação da educação como processo compósito: Tendências e desafios. In J. A. Costa, A. N. Mendes, \& A. Ventura (Orgs.), Políticas e gestão local. Atas do III simpósio sobre organização $e$ gestão escolar (pp. 13-22). Aveiro, Portugal: Universidade de Aveiro.

Barroso, J. (2005). O Estado, a educação e a regulação das políticas públicas. Educação \& Sociedade, 26(92), 725-751.

Barroso, J., \& Afonso, N. (2011). Políticas educativas: Mobilização de conhecimento e modos de regulação. Vila Nova de Gaia, Portugal: Fundação Manuel Leão.

Brandão, M., \& Magalhães, A., (2011). Avaliação educacional, tecnologia política e discurso. Educação, Sociedade \& Culturas, 33, 55-68.

Charters, E. (2003). The use of think-aloud methods in qualitative research: An introduction to think-aloud methods. Brock Education, 12(2), 68-82.

Clímaco, M. (2005). Avaliação de sistemas de educação. Lisboa, Portugal: Universidade Aberta.

Clímaco, M. (2011). Percursos de avaliação externa de escolas em Portugal. Balanços 
e propostas. In Conselho Nacional de Educação, Avaliação das escolas dos ensinos básico e secundário: Perspectivas para um novo ciclo avaliativo (pp. 67-108). Lisboa, Portugal: Conselho Nacional de Educação.

Conselho Nacional de Educação. (2011). Pareceres e recomendações. Lisboa, Portugal: Conselho Nacional de Educação.

Conselho Nacional de Educação. (2015). Avaliação externa das escolas. Disponível em http://www.cnedu.pt/content/edicoes/ seminarios e coloquios/LIVROCNE AVALIA \%C3\%87\%C3\%83O EXTERNA DAS ESCOLAS.pdf

Costa, J. A. (2007). Avaliação, ritualização e melhoria das escolas: À procura da roupa do rei.... In Conselho Nacional da Educação (Org.), Avaliação das escolas - Modelos e processos (Actas do seminário) (pp. 229236). Lisboa, Portugal: Conselho Nacional da Educação.

Costa, J. A., \& Ventura, A. (2002). Avaliação integrada das escolas: Análise em torno das opiniões dos intervenientes. In J. A. Costa, A. Neto-Mendes, \& A. Ventura (Orgs.), Avaliação de organizações educativas. Atas do II simpósio sobre organização e gestão escolar (pp. 106-108). Aveiro, Portugal: Universidade de Aveiro.

Coutinho, P. C. (2015). Metodologia de investigação em ciências sociais e humanas: Teoria e prática (2. ${ }^{\mathrm{a}}$ ed.). Coimbra, Portugal: Almedina.

Faubert, V. (2009). School evaluation: Current practices in OECD and a literature review. OECD Education Working Papers, No. 42, OECD Publishing, Paris. DOI: $10.1787 / 218816547156$

Ferreira, C. (2016). A avaliação externa de escolas em Portugal: Reflexões sobre potencialidades e constrangimentos. Meta: Avaliação, 8(23), 359-379.

Fialho, I. (2011). A avaliação externa das escolas no Alentejo. In B. Nico (Coord.), Escola(s) do Alentejo: Um mapa do que se aprende no sul de Portugal (pp. 262-271). Mangualde, Portugal: Edições Pedago.

Figueiredo, C., Leite, C., \& Fernandes, P. (2014). Modelos internacionais de avaliação externa. A avaliação de escolas em Portugal e na Inglaterra - Origem, fundamentos e percursos. In J. A. Pacheco (Org.), Avaliação externa de escolas: Quadro teórico/ conceptual (pp. 121-146). Porto, Portugal: Porto Editora.

Fonseca, D. (2010). A gestão intermédia nos agrupamentos de escola. Os coordenadores de estabelecimentos e as lideranças periféricas (Tese de doutoramento, Universidade de Aveiro, Portugal). Disponível em http://hdl. handle.net/10773/1115

Fonseca, D., \& Costa, J. A. (2018). Avaliação das escolas e regulação político-normativa: Uma análise de discursos. Movimento Revista de Educação, 5(8), 210-243.

Gonçalves, M. (2012). Educação, trabalho e família. Trajetórias de diplomados universitários. Lisboa, Portugal: Fundação Calouste Gulbenkian / Fundação para a Ciência e a Tecnologia.

Inspeção-Geral da Educação (2001). Plano de Atividades 2001. Lisboa, Portugal: InspeçãoGeral da Educação.

Inspeção-Geral da Educação e Ciência. (2017). Plano de atividades 2017. Disponível em http://www.igec.mec.pt/upload/ Instrumentos Gestao/IGEC PA 2017.pdf

Lima, L. (2011). Administração escolar: Estudos. Porto, Portugal: Porto Editora.

Mendes, M. (2009). Os sete pecados da governação global: Paulo Freire e a reinvenção das possibilidades de uma pedagogia democrática e emancipatória da educação. Revista Lusófona de Educação, 14, 61-76.

OCDE. (2013). Synergies for better learning: An international perspective on evaluation and assessment. OECD reviews of evaluation and assessment in education. OECD Publishing. Disponível em https://www.oecd.org/ 
education/school/Synergies $\% 20$ for $\% 20$ Better\%20Learning Summary.pdf

Pacheco, J. A. (Org.). (2014). Avaliação externa de escolas: Quadro teórico/conceptual. Porto, Portugal: Porto Editora.

Pacheco, J. A. (2015). Relatório do projeto AEENS - Impacto e efeitos da avaliação externa. In Conselho Nacional de Educação, Avaliação Externa das escolas (pp. 33-50). Lisboa, Portugal: Conselho Nacional de Educação. Disponível em: http://www.cnedu.pt/content/edicoes/ seminarios e coloquios/LIVROCNE AVALIA \%C3\%87\%C3\%830 EXTERNA DAS ESCOLAS.pdf

Santiago, P., Donaldson, G., Looney, A., \& Nusche, D. (2012). OECD reviews of evaluation and assessment in education: Portugal 2012. OECD Publishing. Disponível em: https://www.oecd-ilibrary. org/education/oecd-reviews-of-evaluationand-assessment-in-education-portugal2011 9789264117020-en;jsessionid=1JixAF wTUPkv5DEZJlOe5imY.ip-10-240-5-81

Santos, B. S. (2001). Os processos de globalização. In B. S. Santos (Org.). Globalização: Fatalidade ou utopia? (3. ${ }^{\mathrm{a}}$ ed., pp. 31-106). Porto, Portugal: Edições Afrontamento.

Silvestre, M. (2013). A avaliação das escolas. Avaliação nas escolas (Tese de doutoramento não publicada). Universidade de Évora, Évora, Portugal.

Terwee, C. B., Bot, S. D. M., de Boer, M. R., van der Windt, D. A. W. M., Knol, D. L., Dekker, J., ... de Vet, H. C. W. (2007). Quality criteria were proposed for measurement properties of health status questionnaires. Journal of Clinical Epidemiology, 60(1), 34-42. DOI: 10.1016/j.jclinepi.2006.03.012

Tristão, E. (2016). A autoavaliação como instrumento das políticas de avaliação externa das escolas (Tese de doutoramento não publicada). Universidade de Lisboa, Lisboa, Portugal.
Tuckman, B. W. (2012). Manual de investigação em educação (4. ${ }^{\text {a }}$ ed.). Lisboa, Portugal: Fundação Calouste Gulbenkian.

Ventura, A. (2006). Avaliação e inspeção das escolas: Estudo de impacte do Programa de Avaliação Integrada (Tese de doutoramento não publicada). Universidade de Aveiro, Aveiro, Portugal.

\section{E G I S L A Ç Ã O}

Decreto Regulamentar n. ${ }^{\circ}$ 15/2012, de 27 de janeiro - Ministério da Educação e Ciência. Diário da República, 1. ${ }^{a}$ Série - N. ${ }^{\circ}$ 20/2012, pp. 502-504.

Decreto Regulamentar n. ${ }^{\circ} 81-\mathrm{B} / 2007$, de 31 de julho - Ministério da Educação. Diário da República n. ${ }^{\circ}$ 146/2007, $3^{\circ}$ Suplemento, Série I, p. 4902- (21).

Decreto-Lei n. ${ }^{\circ}$ 125/2011, de 29 de dezembro - Ministério da Educação e Ciência. Diário da República n. ${ }^{\circ}$ 249/2011, Série I, pp. 54985508.

Decreto-Lei n. ${ }^{\circ}$ 251-A/2015, de 17 de dezembro - Presidência do Conselho de Ministros. Diário da República n. ${ }^{\circ}$ 246/2015, $1 .^{\circ}$ Suplemento, Série I, pp. 9778- (2) a 99778(11).

Decreto-Lei n. ${ }^{o}$ 75/2008, de 22 de abril Ministério da Educação. Diário da República n. ${ }^{\circ}$ 79, I. Série.

Despacho Conjunto n. ${ }^{\circ} 370 / 2006$, de 3 de maio - Ministério da Educação. Diário da República n. ${ }^{\circ} 85,2 .^{\text {a Série, p. } 6332 .}$

Despacho n. ${ }^{\circ}$ 13342/2016 - Ministério da Educação e Ciência. Diário da República n. ${ }^{\circ}$

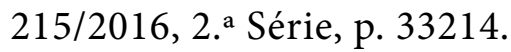

Lei n. ${ }^{\circ} 31 / 2002$, de 20 de dezembro - Ministério da Educação. Diário da República - I. Série-A, n. ${ }^{\circ}$ 294, p. 7952.

Proposta de Lei n. ${ }^{\circ}$ 13/IX - Assembleia da República (2002). Diário da Assembleia da República, II Série - A, N.o 13/IX/1, p. 1130. Aprova o Sistema de Avaliação da Educação e do Ensino não Superior, desenvolvendo o 
regime previsto na Lei n. ${ }^{\circ} 46 / 86$, de 14 de outubro - Lei de Bases do Sistema Educativo.

Disponível em: https://www.parlamento. pt/Paginas / PageNotFound Error. aspx? requestUrl=https://www.parlamento. $\mathrm{pt} /$ Paginas/PaginaIndisponivel.aspx
INSPECTORATE'S INTERVENTION IN External School Assessment: A STUDY BASED ON SCHOOL PRINCIPALS PERCEPTIONS

\section{Abstract}

In Portugal, the system of evaluation of nonhigher education and teaching appears in 2002, with the publication of Law nr. 31/2002, determining that the schools are subjected to external evaluation processes. This evaluation process was handed over to the School Inspectorate since 2007, being this one of the main domains of the inspective intervention. The present study aims to examine how is perceived, by school principals of Portuguese public schools, the role of the inspection in the process of the External Evaluation of Schools. With a descriptive nature, the study relied on a survey application, answered by 111 school principals of mainland Portugal. The results suggest that the External Evaluation of Schools is an inspective activity valued by the school principals and developed in alignment, on the one hand, with the mission and functions of the School Inspectorate in the educational system, and, on the other, with the objectives enshrined in law for that activity. Also, it is showed that the school principals perceived this activity as an opportunity to claim the principal role and accreditation of their leadership in the exercise of their autonomy.

KEYWORDS: School inspectorate; External evaluation of schools; School principals 


\section{INTERVENCIÓN DE INSPECCIÓN EN LA EVALUACIÓN ESCOLAR EXTERNA: UN ESTUDIO BASADO EN LAS PERCEPCIONES DE LOS DIRECTORES}

DE LAS ESCUELAS

\section{RESUMEN}

En Portugal, el sistema de evaluación de la educación y de la enseñanza no superior surge en 2002, con la publicación de la Ley n. ${ }^{\circ} 31 / 2002$, determinando por la misma vía jurídica y normativa que las escuelas sean sometidas a procesos de evaluación externa. Este proceso de evaluación fue confiado a la Inspección de la Educación, a partir de 2007, pasando este a ser uno de los principales ámbitos de la intervención inspectiva. El presente estudio pretende examinar cómo es percibido, por los directores de las escuelas públicas de Portugal, el papel de la Inspección en el proceso de Evaluación Externa de las Escuelas. Con un carácter descriptivo, el estudio se ha apoyado en la aplicación de un cuestionario, contestado por 111 directores del territorio de Portugal continental. Los resultados muestran que la Evaluación Externa de las Escuelas es una actividad inspectiva valorada por los directores de las escuelas y desarrollada en línea con, por un lado, con la misión y funciones de la inspección de educación en el sistema educativo, y, por otro, con los objetivos consagrados, en la ley, a esa actividad. Aún, evidenciase que los directores de las escuelas perciben esta actividad como una oportunidad de afirmación de la figura de director, de acreditación de su liderazgo en el ejercicio de su autonomía.

Palabras Clave: Inspección de la educación; Evaluación externa de las escuelas; Directores de las escuelas

\footnotetext{
${ }^{\text {I }}$ Centro de Investigação em Didática e Tecnologia na Formação de Formadores - CIDTFF, Departamento de Educação e Psicologia, Universidade de Aveiro, Portugal. ORCID: 0000-0001-7080-9081

${ }^{\text {II }}$ Centro de Investigação em Didática e Tecnologia na Formação de Formadores - CIDTFF, Departamento de Educação e Psicologia, Universidade de Aveiro, Portugal. ORCID: 0000-0002-3545-1173

${ }^{\text {III }}$ Departamento de Educação e Psicologia, Universidade de Aveiro, Portugal. ORCID: 0000-0002-7869-8029
} 